\title{
PELATIHAN PEMBUATAN MEDIA PEMBELAJARAN IPA SD BERBASIS EKSPERIMEN BAGI GURU GURU SD GUGUS VIII KECAMATAN KUBUTAMBAHAN
}

\author{
Putu Budi Adnyana 1,*, Desak Made Citrawathi ${ }^{2}$, Putu Artawan ${ }^{3}$ \\ 1 Jurusan Pendidikan Biologi. Universitas Pendidikan Ganesha, Indonesia \\ 2Jurusan Pendidikan Biologi. Universitas Pendidikan Ganesha, Indonesia \\ ${ }^{3}$ Jurusan Pendidikan Fisika. Universitas Pendidikan Ganesha, Indonesia
}

\begin{abstract}
Abstrak
Guru-guru Sekolah Dasar (SD) sekolah mitra, yang tergabung dalam gugus VIII Kecamatan Kubutambahan Kabupaten Buleleng yang terdiri dari lima SD, yaitu: SD 1 Pakisan 1, SD 2 Kelandis, SD 3 Pakisan 3, SD 4 Pakisan 2 dan SD 5 Mengandang mengalami permasalahan dalam pembelajaran IPA berbasis eksperimen sesuai dengan tuntutan stándar proses dan kurikulum. Berdasarkan hasil refleksi dan kajian mendalam terhadap permasalahan dan akar permasalahan bersama dengan guru mitra dan kepala sekolah, maka disepakati pemecahan masalah berupa kegiatan pelatihan dengan tujuan: (1) mengembangkan media pembelajaran IPA berbasis eksperimen yang dilengkapi perangkat pembelajaran seperti Lembar Kerja Siswa (LKS), pembuatan media pembelajan dan pedoman cara menggunakan media pembelajaran IPA SD yang dibuat, (2) meningkatkan keterampilan guru membuat media IPA berbasis eksperimen dan mengimplementasikannyadalam pembelajaran IPA. Target luaran pada kegiatan ini adalah: (1) Perangkat pendukung pembelajaran (RPP dan LKS) yang dilengkapi dengan media pembelajaran IPA SD berbasis eksperimen serta pedomannya untuk mendukung pembelajaran IPA SD, (3) Artikel pengembangan media pembelajaran IPA berbasis eksperimen.Untuk mencapai tujuan dan target tersebut, pendekatan yang digunakan adalah pelatihan dan pendampingan. Kegiatan pelatihan dilakukan untuk meningkatkan kemampuan dan keterampilan guru mitra dalam merancang dan membuat media pembelajaran IPA SD berbasis eksperimen. Kegiatan pendampingan dilakukan untuk membantu guru menyelesaikan produk yang menjadi target kegiatan ini dan dapat mengimplementasikannya di kelas. Kegiatan pelatihan dan pendampingan dilakukan secara bertahap dan terintegrasi.Produkutama dari kegiatan P2M ini adalah media pembelajaran IPA SD berupa LKS eksperimen sederhana berbasis pertanyaan. Hasil evaluasi pelaksanaan P2M ini menunjukkan bahwa P2M ini bermanfaat untuk menunjang proses pembelajaran IPA di SD.
\end{abstract}

\section{Pendahuluan}

Media merupakan salah satu komponen yang menentukan kualitas pembelajaran. Media yang menarik dan dapat memfasilitasi siswa belajar memudahkan siswa dalam memahami meteri yang dibelajarkan. Mengingat peran media sangat penting dalam pembelajaran, maka media perlu dibuat dengan baik agar dapat digunakan dalam pembelajaran. Pembelajaran IPA di SD sangat penting untuk memberikan pengetahuan tentang alam, keterampilan proses, dan sikap ilmiah yang dibutuhkan untuk mempelajari alam itu sendiri dan penggunaaannya dalam kehidupan sehari-hari. Pembelajaran IPA tidak cukup diceramahkan, tetapi harus dibelajarkan dengan memberi pengalaman langsung, misalnya melalui kegiatan ekpserimen sederhana. Pengalaman berlajar langsung yang diperoleh dalam pembelajaran IPA dapat memberikan pemahaman bermakna, keterampilan, dan sikap positif bagi siswa.Salah satu pendekatan pembelajaran yang dapat diterapkan untuk mempelajari dan memahami konsep IPA di SD adalah dengan pendekatan induktif. Dalam pendekanan induktif siswa diberikan pengalaman belalajar membuat kesimpulan berdasarkan hasil eksperimen sederhana yang dibuat dan dilaksanakan oleh siswa. Melalui kegiatan eksperimen siswa dapat melatih keterampilan proses sains, mempelajari konsep sains secara bermakna dan mengembangkan sikap ilmiah siswa. Dengan demikian siswa akan menyadari bahwa materi IPA yang dibelajarkan guru di kelas (sekolah) mudah dipelajari dan bermanfaat dalam kehidupan sehari-hari.Pembelajaran IPA di SD dengan menggunakan pendekatan induktif melalui kegiatan eksperimen sederhana memerlukan media yang relevan. Oleh karena itu, media yang digunakan dalam pembelajaran IPA perlu dirancang dengan baik dengan menggunakan bahan-bahan yang ada di 
lingkungan sekitar sehingga pembelajaran IPA menjadi bermakna (meaningful learning). Untuk bisa merancang dan membuat media IPA SD berbasis eksperimen, guru harus memiliki wawasan dan keterampilan membuat media. Wawasan dan keterampilan membuat media IPA dapat di peroleh melalui kegiatan pelatihan dan pendampingan terintegrasi.

Sekolah Dasar (SD) di Kecamatan Kubutambahan dikelompokan menjadi delapan gugus yang tersebar di wilayah Timur Kabupaten Buleleng, Provinsi Bali. Peta wilayah Kecamatan Kubutambahan terlihat sebagai Gambar 1.

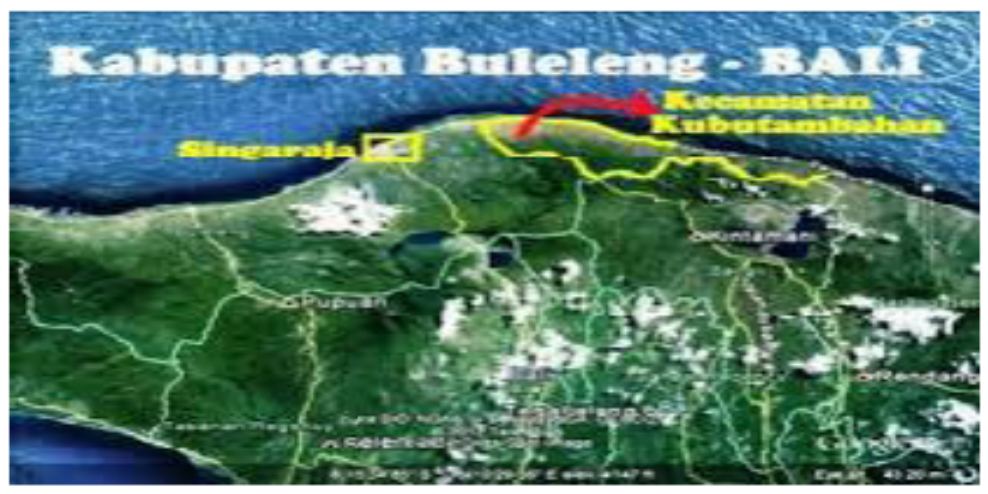

Gambar 1. Peta Wilayah Kecamatan Kubutambahan

Gugus VIII SD Kecamatan Kubutambahan berlokasi di Desa Paksisan terdiri dari 5 (lima) SD yang tersebar yang tersebar dalam 4 dusun, yaitu SD 1 Pakisan 1 (Tegehe), SD 2 Klandis, SD3 Pakisan 1 (Tegehe), SD 4 Pakisan 2 (Desa), dan SD 5 Mengandang. Jarak sekolah mitra dengan lokasi kampus $21 \mathrm{~km}$ dan dua dusun lokasinya di perbukitan. Hasil observasi dan pengumpulan data (dokumentasi) diperoleh hasil bahwa rata-rata NEM untuk matapelajaran IPA masih rendah. Hal ini menunjukkan penguasaaan materi IPA siswa SD rendah. Kegiatan pembelajaran yang dilakukan oleh guru IPA SD di Gugus VIII masih didominasi dengan metode ceramah, konsep-konsep IPA yang dibelajarkan sangat abstrak tanpa menggunakan alat peraga atau media pembelajaran agar siswa lebih mudah menerima dan memahami konsep-konsep IPA yang dibelajarkannya. Padahal hakikat pembelajaran IPA SD adalah sebagai wahana dalam memberi pengalaman belajar langsung kepada siswa dalam menemukan dan mempelajari konsep IPA. Salah satu contoh kegiatan pembelajaran yang dilakukan oleh salah satu guru IPA SD terlihat sebagai Gambar 2 berikut ini.
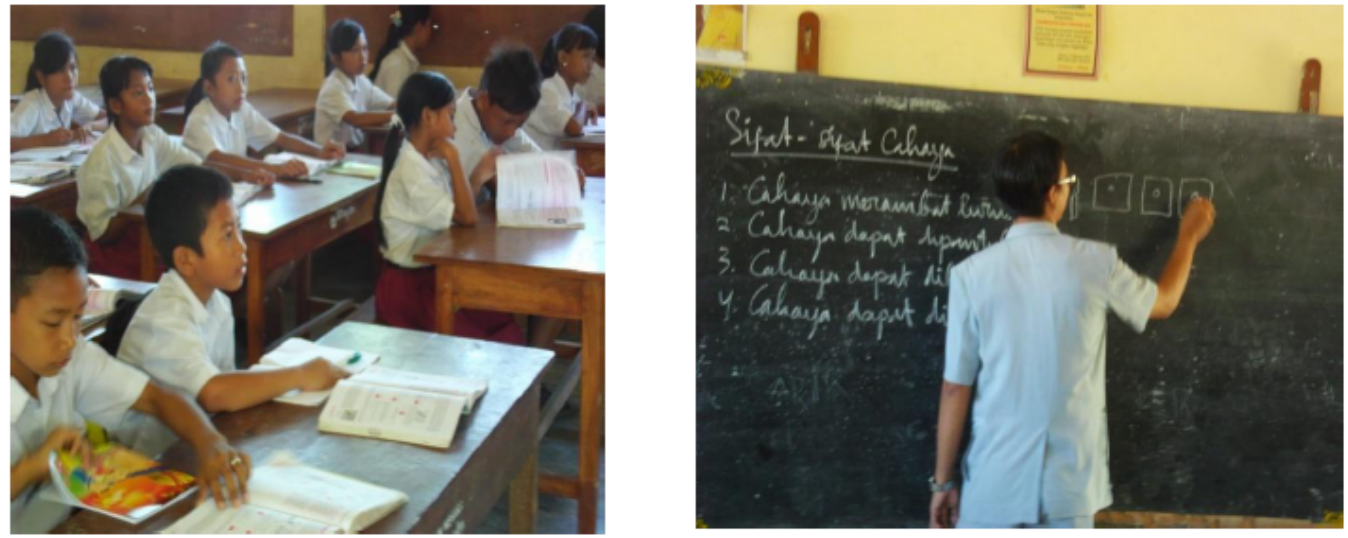

Gambar 2. Kegiatan Pembelajaran IPA SD

Dari Gambar 2 tersebut terlihat bahwa proses belajar mengajar dalam pembelajaran IPA pengalaman belajar siswa sangat miskin dan kegiatan siswa lebih banyak mencatat apa yang disampaikan guru dan apa yang ditulis guru di papan tulis, hal ini menunnjukkan pembelajaran IPA SD tidak bermakna. Pemakaian media pembelajaran untuk memotivasi siswa belajar dan lebih memudahkan siswa memahami konsep-konsep IPA tidak tampak dalam pembelajaran tersebut. Padahal materi pembelajaran IPA SD dapat dibelajarkan dengan menggunakan media dari bahan-bahan yang ada disekitar siswa, di rumah atau di sekolah dan kemas dalam bentuk eksperimen. Penggunaan media IPA berbasis eksperimen memberikan banyak pengalaman belajar dalam melatih keterampilan proses IPA, seperti mengamati, membuat hipotesis, mengukur, mengkomuniikasikan, membuat eksperimen, dan meyimpulkan.

Kegiatan wawancara yang dilakukan pada beberapa guru IPA SD pada Guru Gugus VIII Desa Pakisan terkait dengan perangkat, proses pembelajaran, serta penggunaan media pembelajaran terungkap 
beberapa permasalahan sebagai berikut ini. 1) Perangkat pembelajaran berupa Silabus dan RPP IPA disusun bersama oleh guru di gugus, sedangkan dalam pelaksanaan pembelajaran RPP tersebut hanya digunakan sebagai contoh saja. Dalam RPP ada tercantum menggunakan media pembelajaran namun tidak disiapkan dan cara membuat media pembelajaran serta cara penggunaan media belum dipahami. Hal ini disebabkan karena guru kurang terlatih membuat media pembelajaran, padahal media pembelajaran sangat diperlukan dalam pembelajaran IPA di SD. 2) Proses pembelajaran IPA di Gugus VIII jarang menggunakan alat bantu atau media pembelajaran. Alasannya antara lain karena keterbatasan waktu untuk membuat media pembelajaran, serta para guru mengalami kesulitan untuk membuat media pembelajaran tersebut. 3) Guru beranggapan bahwa pembelajaran IPA di SD menggunakan media memerlukan waktu yang lebih lama. Padahal pembelajaran IPA menggunakan media pembelajaran lebih menarik dan menyenangkan. Siswa dapat pengalaman langsung dan IPA tidak lagi bersifat abstrak. Untuk mengatasi masalah ini, maka pembelajaran IPA SD seharusnya menggunakan media pembelajaran seharusnya dikemas sedemikian rupa sehingga pembelajaran IPA menjadibermakna, menarik, efektif dan efisien. 4) Pembuatan media pembelajaran dianggap memerlukan biaya yang banyak. Hal ini menyebabkan guru-guru enggan menggunakan media pembelajaran, padahal bahan-bahan untuk membuat media pembelajaran ada dan banyak dilingkungan sekitar dan mudah didapat. 5) ada beberapa SD yang tergabung pada gugus ini telah tersedia Kit IPA SD, namun jarang digunakan dalam proses pembelajaran.

\section{Metode}

Untuk mengatasi permasalahan yang dialami para guru IPA SD di Gugus VIII Kecamatan Kubutambahan, maka solusi permasalahan yang ditawarkan adalah penyelenggaraan inservice berupa pelatihan dan pendampingan. Pelatihan dan pendampingan yang dilakukan adalah: (1) Pelatiahan dan pendampingan mengembangkan ketrampilan dan kretivitas guru IPA SD dalam merancang dan membuat media pembelajaran IPA SD berbasis eksperimen serta petunjuknya, (2) Pelatihan dan pendampingan membuat LKS berbasis eksperimen menggunakan bahan-bahan yang ada di lingkungan sekitar. Kegiatan pelatihan dilakukan secara bertahap dan terintegrasi, yaitu pelatihan dan pendampingan agar guru-guru betul-betul terampil membuat LKS berbasis eksperimen dan mengimplementasikannya di kelas.

\section{Hasil Dan Pembahasan}

Pendekatan yang digunakan terhadap permasalahan sekolah mitra adalah sebagai berikut. a) Memberikan pelatihan guru IPA SD mengidentifikasi konsep kunci IPA SD yang dapat dibelajarkan dengan menggunakan media pembelajaran berbasis eksperimen. b) Memberikan pelatihan mengidentifikasi fakta atau fenomena kehidupan sehari-hari yang relevan dengan beberapa konsep kunci yang telah diidentifikasi. c) Memberikan pelatihan dan pendampingan merancang dan membuat media pembelajaran IPA SD berbasis eksperimen berupa LKS eksperimen sederhana berbasis pertanyaan dengan menggunakan bahan-bahan yang ada di lingkungan sekitar. d) Memberikan pelatihan dan pendampingan merancang dan membuat pedoman penggunaan media pembelajaran dan LKS eksperimen sederhana berbasis pertanyaan. e) Melakukan pendampingan guru dalam mengimplementasikan penggunaan media pembelajaran IPA SD berbasis eksperimen dalam pembelajaran IPA dengan mengunakan pola Lesson Study. 
Prosedur dan langkah-langkah yang dilakukan adalah seperti digambarkan pada diagram alur Gambar 3 berikut.

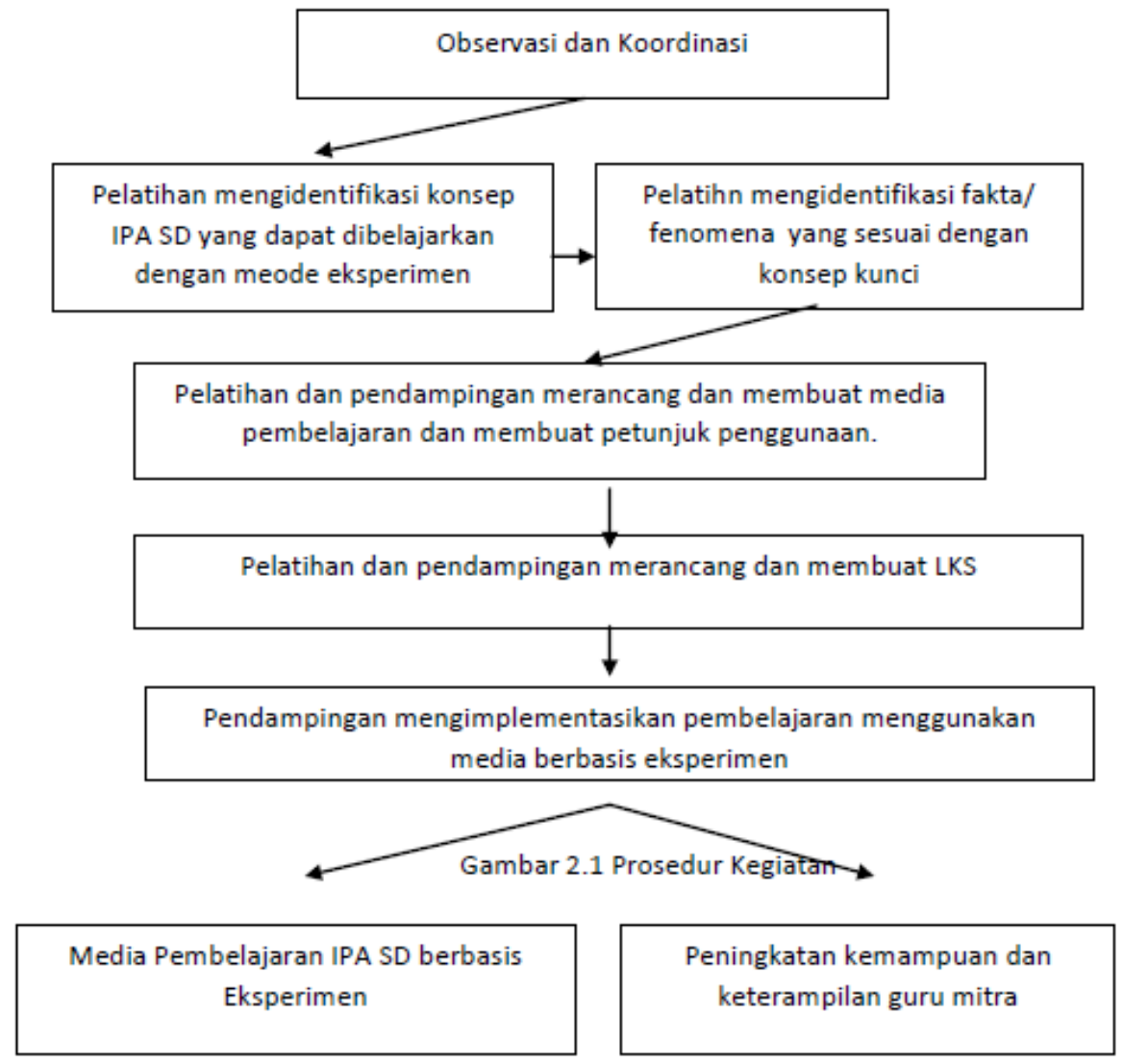

Ganbar 3 Prosedur Kegiatan

1. Tahap Persiapan Kegiatan . Untuk memperlancar proses pelatihan yang dilakukan, maka diperlukan panduan pembuatan media pembelajaran IPA berbasis eksperimen berupa LKS eksperimen sederhana berbasis pertanyaan. LKS Eksperimen sederhana berbasis pertanyaan dibuat dengan memperhatikan hasil analisis kurikulum dan bahan-bahan ekpslerimen yang mudah diperoleh di lingkungan sekitar.

2. Tahap Pelaksanaan Kegiatan. Pelatihan pembuatan media pembelajaran IPA SD diikuti oleh 17 orang guru SD Gugus VIII Kecamatan Kubutambahan yang berasal dari 5 sekolah, yaitu 1) SD Negeri 1 Pakisan, 2) SD Negeri 2 Pakisan, 3) SD Negeri 4 Pakisan, dan 4) SD Negeri 5 Pakisan. Pelatihan diawali dengan laporan ketua pelaksana PkM dan dilanjutkan sambutan dan pembukaan kegiatan secara resmi oleh Kepala UPP Kecamatan Kubutambahan (Made Kawiatha, S.Pd.). Pelatihan dihadiri oleh Pengawas SD Gugus VIII Kecamatan Kubutambahan (Ni Ketut Riati, S.Pd.) dan Kepala Sekolah SD Gugus VIII dibuka secara resmi. Narasumber pada kegiatan pelatihan adalah Prof. Dr. I Ketut Suma, M.S. dan didampingi instruktur Prof. Dr. Putu Budi Adnyana, M.Si., Dr. Desak Made Citrawathi, dan Putu Artawan, S.Pd., M.Si.

Setelah mengikuti kegiatan P2M, peserta pelatihan dari sekolah mitra mendapatkan wawasan beberapa pengetahuan dan keterampilan sebagai berikut: a) Memahami peranan media pembelajaran dalam pembelajaran IPA SD. b) Dapat merancang pembelajaran yang memenuhi standar proses. c) Dapat membuat media pembelajaran IPA beberbasis eksperimen. d) Dapat membuat Lembar Kerja Siswa (LKS) ekspereimen sederhana berbasis pertanyaan dengan menggunakan bahan yang ada di lingkungan sekitar dan, e) Respon peserta sangat positif dan melakukan kegiatan penuh dengan kegembiraan Aktivitas yang dilakukan selama pelatihan disajikan dalam bentuk visual terlampir.

Media dan LKS yang dibuat sudah memenuhi syarat atau layak di gunakan dalam pembelajaran IPA SD. Darmojo \& Kaligis (1992), menguraikan syarat-syarat LKS yang baik adalah sebagai berikut. (1) Syarat-syarat didaktik merupakan syarat yang terkait dengan asas-asas pembelajaran yang efektif seperti: a) memperhatikan perbedaan individu, b) menekankan pada proses penemuan, c) memiliki variasi stimulus melalui berbagai media dan kegiatan, d) dapat mengembangkan kemampuan komunikasi social, emosional, moral, dan estetika pada diri siswa, dan 5) pengalaman belajar ditentukan oleh tujuan 
pengembangan pribadi siswa (intelektual, emosional dan sebagainya), dan bukan ditentukan oleh materi pelajaran. (2) Syarat-syarat kontruksi merupakan syarat-syarat yang berkenaan dengan penggunaan bahasa, susunan kalimat, kosa kata, tingkat kesukaran, dan kejelasan. Syarat-syaratyang harus dipenuhi adalah: a) menggunakan bahasa sesuai dengan tingkat perkembangan siswa, b) menggunakan struktur kalimat yang jelas, c) memiliki tata urutan pelajaran yang sesuai dengan tingkat kemampuan siswa, d) hidarkan pertanyaan yang sangat terbuka, e) tidak mengacu pada buku sumber diluar kemampuan siswa, f) menyediakan ruangan yang cukup untuk tempat menulis atau menggambar, g) menggunakan kalimat sederhana dan pendek, h) menggunakalan lebih banyak ilustrasi dari pada kata-kata, i) dapat digunakan oleh siswa yang lamban maupun yang cepat, j) ada identitas untuk memudahkan administrasinya. (3) Syarat-syarat teknis merupakan syarat terkait dengan tulisan, gambar, dan penampilan. Syarat-syarat yang harus dipenuhi: a) tulisan harus jelas, mudah dibaca, dan ukurannya serasi dengan gambar, b) gambar jelas, dapat menyampaikan pesan/isi secara efektif, dan c) penampilan menarik dan ada kombinasi gambar dan huruf.

Respon siswa SD dalam pembelajaran IPA sangat postif. Hal ini didasarkan atas hasil pengamatan terhadap aktivitas belajar siswa yang menunjukan bahwa seluruh peserta aktif melakukan kegiatan (percobaan). Hal ini disebabkan karena secara umum media pembelajaran kontekstual IPA SD dapat memberikan pengalaman belajar yang melibatkan siswa baik secara fisik maupun mental. Siswa terlibat secara langsung aktif melakukan kegiatan (hand-on) dan diberi kesempatan beripikir (mind-on) untuk membuat kesimpulan berdasarkan hasil eksplorasi, observasi atau eksperimentasi. Hasil penelitian menunjukkan bahwa pemberian pengalaman belajar lansung dapat memberikan daya retensi $90 \%$ dari apa yang siswa pelajari. Pengalaman belajar siswa dapat daya retensi yang diperoleh siswa dapat dilihat pada kerucut pengalaman belajar (Gambar 4).

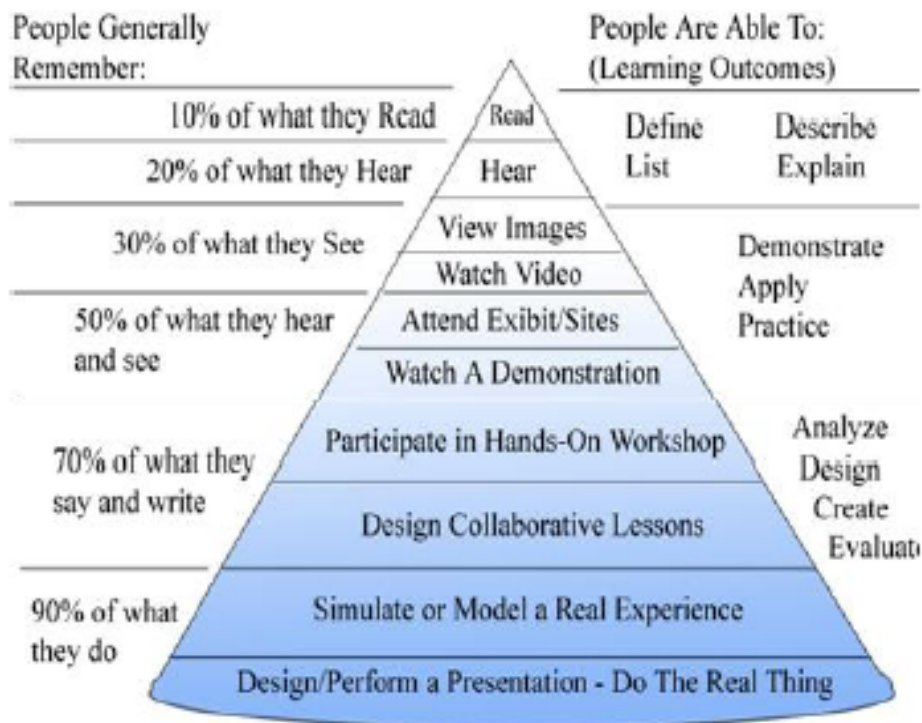

Gambar 4. Kerucup Pembel;alajar Edgar Dale

\section{Simpulan Dan Saran}

Kegiatan P2M yang telah dilaksanakan dapat meberikan manfaat kepada guru SD Gugus VIII Kecamatan Kubutambahan dalam membelajaran IPA di SD. Peserta pelatihan dari sekolah mitra mendapatkan wawasan beberapa pengetahuan tentang: (1) peranan media pembelajaran kontekstual dalam pembelajaran IPA SD, (2) merancang pembelajaran yang memenuhi standar proses, (3) cara membuat media pembelajaran IPA, (4) cara membuat Lembar Kerja Siswa (LKS) eksperimen sederhana berbasis pertanyaan, dan (5) cara mengimplementasikan media pembelajaran dalam pembelajaran.

Guru-guru SD Gugus VIII Kecamatan Buleleng telah mampu membuat media pembelajaran IPA SD berbasis eksperimen. Media yang telah dibuat berupa LKS eksperimen sederhana berbasis eksperimendengan menggunakan bahan-bahan yang ada di lingkungan sekitar

Respon siswa SD dalam pembelajaran IPA sangat postif. Hal ini didasarkan atas hasil pengamatan terhadap aktivitas belajar siswa yang menggunakan media pembelajaran IPAberbais eksperimen. Dalam pembelajaran IPA, seluruh siswa aktif melakukan kegiatan (percobaan) dan bekerja secara antusias dan penuh kegembiraan. 


\section{Daftar Pustaka}

Hamsah, A.S. 1981. Media Audio-Visual untuk Pengajaran, Penerangan dan Penyuluhan. Jakarta: Gramedia.

Johnson, E.B. 2002. Contextual Teaching and Learning: What it is and why it's here to stay. Californea: Corwin Press.

Morrison, G.R., Ross, S.M., Kemp, and Kalman, H.K. 2007. Designing Effective Instruction. United State: John Willey \& Son.

Rohani, A. 1997. Media Instruksional Edukatif. Jakarta: Rineka Cipta.

Smaldiono, S.E, Lowther, D.L. and Russell, J.D.2008. Intructional Technology and Media for Learning (8th . Ed), Upper Saddle River. Pearson Education.

Sudjana dan Rivai, A. 2002. Media Pengajaran. Bandung: Sinar Baru Algesindo

Suparman, A. 2012. Desain Instruksional Modern: Panduan Para Pengajar \& Inovator Pendidikan. Jakarta: Erlangga 